\title{
Lithium catalyst concentration influence on bio-polyols structure and polyurethane adhesives properties
}

\author{
Amanda Martins Nacas ${ }^{1}$, Anne Cristine Chinellato ${ }^{2}$, \\ Demetrio Jackson dos Santos ${ }^{2}$
}

\footnotetext{
${ }^{1}$ Nanoscience and Advanced Materials Graduate Program, Federal University of ABC (UFABC), Santo André, São Paulo, Brasil.

${ }^{2}$ Center for Engineering, Modeling and Applied Social Sciences, Federal University of ABC (UFABC), Santo André, São Paulo, Brasil.

e-mail: amanda.nacas@aluno.ufabc.edu.br, anne.chinellato@ufabc.edu.br, demetrio.santos@ufabc.edu.br
}

\begin{abstract}
Polyol structure can be affected by the catalyst used for its synthesis and may affect the curing kinetics and mechanical strength of the final polyurethane (PU). This work aimed to study the influence of catalyst concentration on the structure of bio-based polyols and on the final properties of the polyurethane adhesive obtained from these polyols. Polyols were investigated by Fourier transform infrared (FTIR), gel permeation chromatography (GPC) and hydroxyl index analysis, with the purpose of investigating the polyols chemical state after the synthesis. Results suggest that higher catalyst concentration led to polyols with higher hydroxyl index and other differences in the polyols structure. The influence of the catalysts concentration on the cure kinetics of the polyurethanes was verified using the Fourier transform infrared (FTIR). In addition, peel strength of PU adhesives was obtained by increasing catalyst concentration on polyol synthesis.
\end{abstract}

Keywords: Bio-polyol, catalyst, adhesives, polyurethane.

\section{INTRODUCTION}

Polyurethane adhesives are widely used because of their formulation versatility, which makes possible to obtain materials with a large range of mechanical properties and adhesion to several types of substrates. Polyurethane properties can be changed by combining different raw materials, as well as by varying the ratio between the isocyanate and the polyol used on its formulation or synthesis [1,2].

Among the components used in polyurethane synthesis, the polyol plays a determining role, it direct influences the morphology and properties of the polyurethane [3, 4]. Likewise, as verified in previous study, polyol structure can be affected by the catalyst type used for the reaction and might affect the curing kinetics and mechanical strength of the PU [5].

Considering the need of developing sustainable materials to replace petroleum-based polyurethanes, several studies have been carried out for the development of PU from renewable sources. Many of those studies were focused on obtaining polyols from vegetable oils and using sustainable, or green, catalysts [6-9].

The effects of traditional catalysts in polyurethane chemical state is already well known [10], in which residues of metal catalysts, as tin-based catalysts, implies into high toxicity and might generate side reactions during PU synthesis. Thereby, tin-free catalysts (organometallic catalysts, metal salts and chelates) have been investigated as alternative to hazardous catalysts, which minimize these adverse effects [11-13].

In this context, our work investigated the influence of lithium organometallic catalyst concentration on polyol structure and consequently on the final adhesive properties of the synthetized PU (peeling), aiming to contribute to development of sustainable and bio-based polyurethanes with tin-free catalyst.

\section{MATERIAL AND METHODS}

\subsection{Polyol synthesis}

Three different bio-based polyester polyols were synthesized using different catalyst concentrations, but with the same type and quantities of renewable raw materials and the same synthesis parameters. Catalyst concen- 
trations were defined based on reaction mechanism and are showed in Table 1. Polyol synthesis was based on alkyd resin reaction, as illustrated in Figure 1. The synthesis compounds and parameters cannot be presented in details due to industrial confidentiality.

Table 1: Catalyst concentrations for polyol synthesis.

\begin{tabular}{|l|l|l|}
\hline \multicolumn{2}{|c|}{ LITHIUM CATALYST CONCENTRATION (wt \%) } \\
\hline POLYOL Li & POLYOL 4Li & POLYOL 15Li \\
\hline 0,022 & 0,1 & 0,34 \\
\hline
\end{tabular}

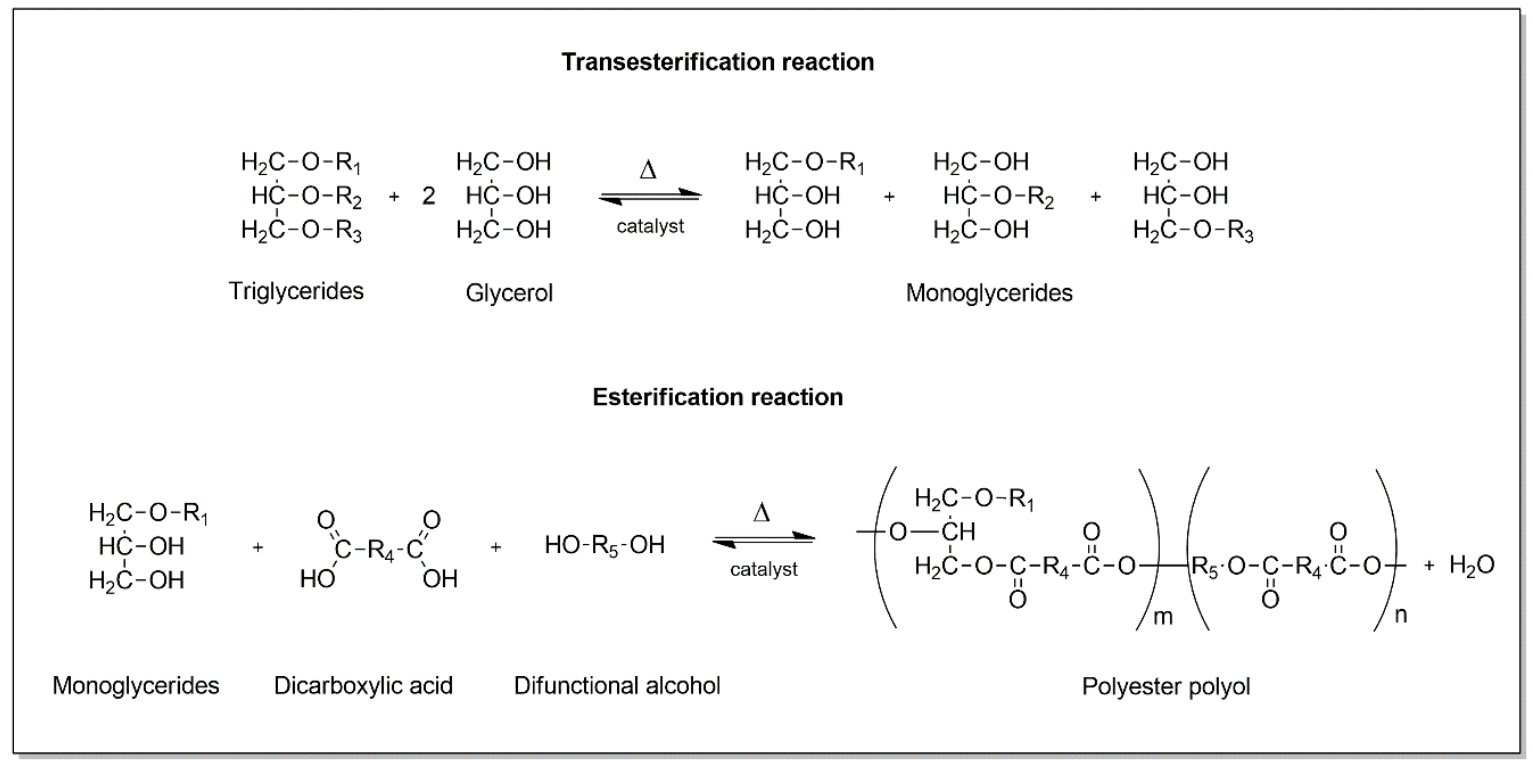

Figure 1: Schema of the polyol synthesis based on an alkyd resin reaction.

\subsection{PU preparation}

PUs were prepared by individually mixing the synthetized polyols with diphenylmethane diisocyanate (MDI), named DESMODUR ${ }^{\circledR} 2460$ M (Covestro, São Paulo, SP/BR), with a NCO:OH molar ratio of 1.1:1, at room temperature for $2 \mathrm{~min}$ at $20 \mathrm{rpm}$ in a $200-\mathrm{mL}$ beaker. PUs were then cured at room temperature for 7 days.

\subsection{Characterization}

\subsubsection{Hydroxyl index}

Hydroxyl index measurement was performed in triplicate, according to ASTM E222, through a titration method using a potentiometric titrator (Metrohm), which consists of the reaction of the terminal hydroxyl groups with organic anhydrides.

\subsubsection{Gel permeation chromatography (GPC)}

Polyols molecular weight was quantified by gel permeation chromatography, using a Waters binary HPLC pump and a Waters 2414 refractive index detector (Jundiai, SP/BR). The samples were dissolved in tetrahydrofuran (THF) at $30^{\circ} \mathrm{C}$. Polystyrene standards were used to obtain calibration curves.

\subsubsection{FTIR spectroscopy}

FTIR spectra were collected using a Perkin Elmer Spectrum (Varian 660) equipment (Jundiai, SP/BR) operating in the attenuated total reflection mode (ATR). Each sample was analyzed using a total of 32 scans performed from 4000 to $600 \mathrm{~cm}^{-1}$ with resolution of $4 \mathrm{~cm}^{-1}$. To investigate the curing kinetics, FTIR spectra were collected at room temperature at different curing times $(0,10,20,30,40,70,130,190,240,360$, and 
$480 \mathrm{~min}$, and 24,120 , and $168 \mathrm{~h}$ ). The results were normalized according to the intensity of the absorption band centered at $2924 \mathrm{~cm}^{-1}$, which is assigned to $v\left(\mathrm{CH}_{2}\right)$ asymmetric stretching. Peeling substrates, after failure, were analyzed by FTIR to determine the laminated sheets failure type as a function of PU groups presence on both laminate surface, $\mathrm{Al}$ and low density polyethylene.

\subsubsection{Brookfield viscosity}

Polyols viscosity were measured after the synthesis of the polyols using a Brookfield viscometer, model RVDV II + PRO (Jundiaí, SP-BR) according to ASTM D2146. The measurements were performed using spindle $\mathrm{n}^{\circ} 27$, at $25^{\circ} \mathrm{C}$ temperature and speed of $100 \mathrm{rpm}$.

\subsubsection{Mechanical properties}

The flexible laminates were composed by commercial LDPE film (Corona treatment), supplied by Nold Politech (Itaquaquecetuba, SP/BR), which were bonded by PU adhesives to Al films, previously deposited onto biaxially oriented polypropylene (BOPP) via vacuum evaporation (PVD), supplied by Vitopel (Mauá, SP/BR). Flexible laminated substrates, for peel tests, were prepared by manual lamination according to a well-established methodology described in details elsewhere [5,14-16], in which, PU adhesive was dissolved in ethyl acetate at a proportion of 1:1 and mixed for $2 \mathrm{~min}$ at $20 \mathrm{rpm}$ and room temperature. The BOPP-Al films were immobilized on a flat surface, and then an application roller was used to apply $2 \mathrm{~mL}$ of the adhesive over the Al surface, resulting into a homogeneous adhesive layer. Subsequently, LBPE film was placed over the adhesive to form BOPP-Al/PU/LDPE laminate. The bonded layers were then cured at room temperature for seven days to ensure full curing of the adhesive. The laminated BOPP-Al/PU/LDPE sheets were then cut into five samples with dimensions of $2.54 \mathrm{~cm} \times 10 \mathrm{~cm}$ for peel testing. Peel strength measurements were performed with a cross-head speed of $0.280 \mathrm{~m} / \mathrm{min}$ at room temperature according to the test method from ASTM Standard F904-98 (2008) using an EMIC DL-200 peel tester (Jundiai, SP-BR). Five samples were tested for each material condition.

\section{RESULTS AND DISCUSSION}

Bio-polyols syntheses occurred in two stages, a transesterification step followed by an esterification (Figure 1). In the transesterification stage hydroxylated molecular structures are obtained and may have functionality equal to one or two (diols), once a non-hydroxylated oil was used as primary raw material [17, 18]. In the esterification step, part of the hydroxyl was consumed in order to obtain the polyester polyol. Remaining hydroxyls were available in the final polyol to react with the isocyanate in the polyurethane synthesis [19]. Hydroxyl index measurements of the synthesized bio-polyols were performed to evaluate the influence of the catalysts concentration on the amount of hydroxyl of them.

According to the results presented in Table 2, the increase of the lithium-based catalyst concentration, from Polyol Li to Polyol 4Li, led to an increase of hydroxyl content and a reduction of polyol viscosity. This combined behavior might be associated with the formation of branches in the polyol chemical structure. This could be occurring due to an excess of glycerol that could act as branching agent during the synthesis of polyesters (esterification process) [20,21]. The high glycerol content might be resulted from reversion reaction during transesterification. Additionally, the presence of unreacted glycerol could also contribute to reduction of polyol viscosity. However, complementary studies are needed to confirm the occurrence of branches. Comparison of Polyol 4Li and 15Li revealed no significant changes on hydroxyl index and viscosity.

Table 2: Properties of synthesized polyols.

\begin{tabular}{|c|c|c|c|c|c|}
\hline & $\begin{array}{c}\text { HYDROXYL } \\
\text { INDEX } \\
\left(\mathrm{mg} \mathrm{KOH}^{-1}\right)\end{array}$ & $\begin{array}{c}\text { BROOKFIELD } \\
\text { VISCOSITY } \\
\text { (MPa.s) } \\
\end{array}$ & $\begin{array}{c}M_{N} \\
\left(g \cdot m o r^{1}\right)\end{array}$ & $\begin{array}{c}M_{W} \\
\left(g \cdot \mathrm{mol}^{1}\right)\end{array}$ & $\begin{array}{c}\text { POLYDISPERSITY } \\
\text { (PDI) }\end{array}$ \\
\hline POLYOL Li & $162.23 \pm 7.01$ & 1200 & $950 \pm 03$ & $1715 \pm 06$ & $1.80 \pm 0.010$ \\
\hline POLYOL 4Li & $179.65 \pm 3.58$ & 1010 & $848 \pm 12$ & $1472 \pm 44$ & $1.74 \pm 0.030$ \\
\hline POLYOL 15Li & $177.13 \pm 2.06$ & 1010 & $922 \pm 11$ & $1514 \pm 03$ & $1.64 \pm 0.020$ \\
\hline
\end{tabular}

It is also possible to identify a tendency of reduction in the molecular weight of the polyol and in its polydispersity with the increase of the catalyst concentration (Table 2). These results strengthen the argument 
of reversion reaction during transesterification based on: i. an effective transesterification should increase PDI values, due to the heterogeneity caused by simultaneous presence of mono and diglycerides; ii. high contents of monoglycerides, absence of reverse reaction during transesterification, generates a higher degree of conversion during esterification, which results into higher molar mass. The polymer molecular weight influences polyol viscosity, for example, the increase in molecular weight promotes an increase in the properties of impact strength, elongation at break and viscosity due to the increase in entanglements and intermolecular forces [22-24].

FTIR was applied to investigate polyols chemical state. Figure 2 shows a comparison of the normalized FTIR spectra from polyol Li, 4Li and $15 \mathrm{Li}$, in the region from $4000 \mathrm{~cm}^{-1}$ to $600 \mathrm{~cm}^{-1}$. Some characteristics polyol bands were assigned in Figure 1(a): the band at $3450 \mathrm{~cm}^{-1}$ indicates the presence of hydroxyl groups; that band at $3008 \mathrm{~cm}^{-1}$ is attributed to the $(\mathrm{CH})$ stretching; $2924 \mathrm{~cm}^{-1}$ to methylene asymmetric stretching $v_{\mathrm{as}}\left(\mathrm{CH}_{2}\right)$ and $2854 \mathrm{~cm}^{-1}$ to the methylene symmetrical stretching $v_{\mathrm{ss}}\left(\mathrm{CH}_{2}\right)[3,25,26]$. The hydroxyl band intensities presented in Figure 2(a) are in accordance with the hydroxyl index obtained by the titration.
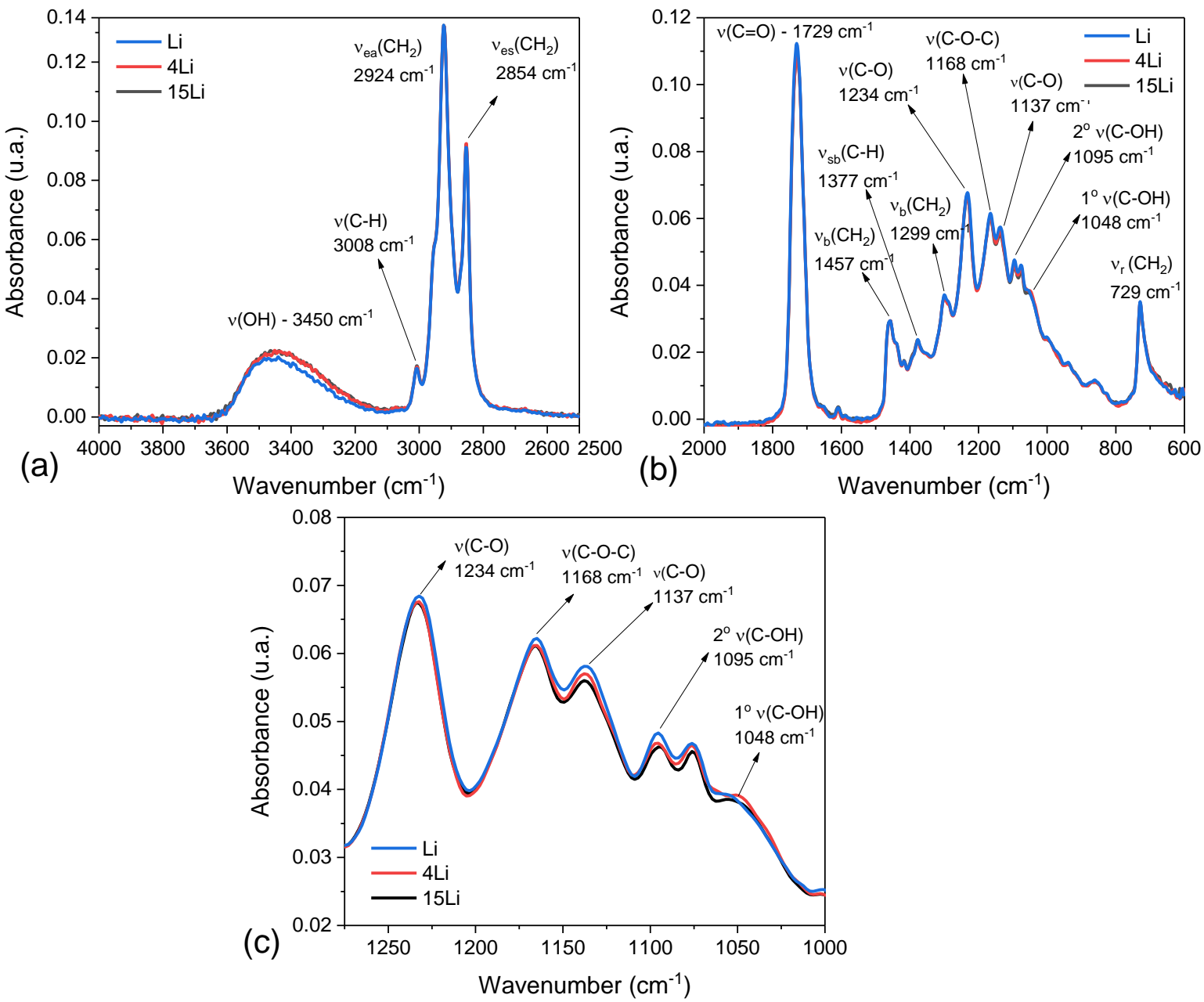

Figure 2: Normalized FTIR spectra of polyols (a) from 4000 to $600 \mathrm{~cm}^{-1}$, (b) from 2000 to $600 \mathrm{~cm}^{-1}$ and (c) magnification of the regions at $1250-1000 \mathrm{~cm}^{-1}$.

Figure 2 (b) presented characteristic ester carbonyl bands, assigned to $v(\mathrm{C}=\mathrm{O})$ stretching at $1731 \mathrm{~cm}-1$, peaks at $1234 \mathrm{~cm}-1$ and $1137 \mathrm{~cm}-1$ are assigned to $v(\mathrm{C}-\mathrm{O})$ stretching, and the band at $1168 \mathrm{~cm}-1$ is assigned to $v(\mathrm{C}-\mathrm{O}-\mathrm{C})$ stretching $[3,26-28]$. In addition, hydroxyl characteristic bands might also be identified at 1048 cm-1 (primary hydroxyl stretching) and $1096 \mathrm{~cm}-1$ (secondary hydroxyls stretching) [29]. Figure 2 (c) revealed that the polyol with lower lithium concentration presented the highest intensity of ester groups (1234 cm-1, $1137 \mathrm{~cm}-1$ and $1168 \mathrm{~cm}-1$ ) suggesting a higher polymerization rate. During the polyol synthesis, in the esterification reaction, a higher polymerization rate leads to a higher consumption of the hydroxyls present in the raw material and an increase in the amount of ester bonds formed [19, 30, 31]. 
FTIR spectra as a function of polyurethane curing time are shown in Figure 3. The curing reaction between the isocyanate and the polyol can be confirmed by the increasing of urethane band, assigned to amine group $(v-\mathrm{NH})$ at $3325 \mathrm{~cm}^{-1}$, whereas by the decreasing of isocyanate peak $\left(v-\mathrm{N}=\mathrm{C}=\mathrm{O}\right.$ in $\left.2263 \mathrm{~cm}^{-1}\right)$ and at last, the wide band corresponding to hydroxyl $\left(v-\mathrm{OH}\right.$ at $\left.3400 \mathrm{~cm}^{-1}\right)$ tend to disappear [32-34].
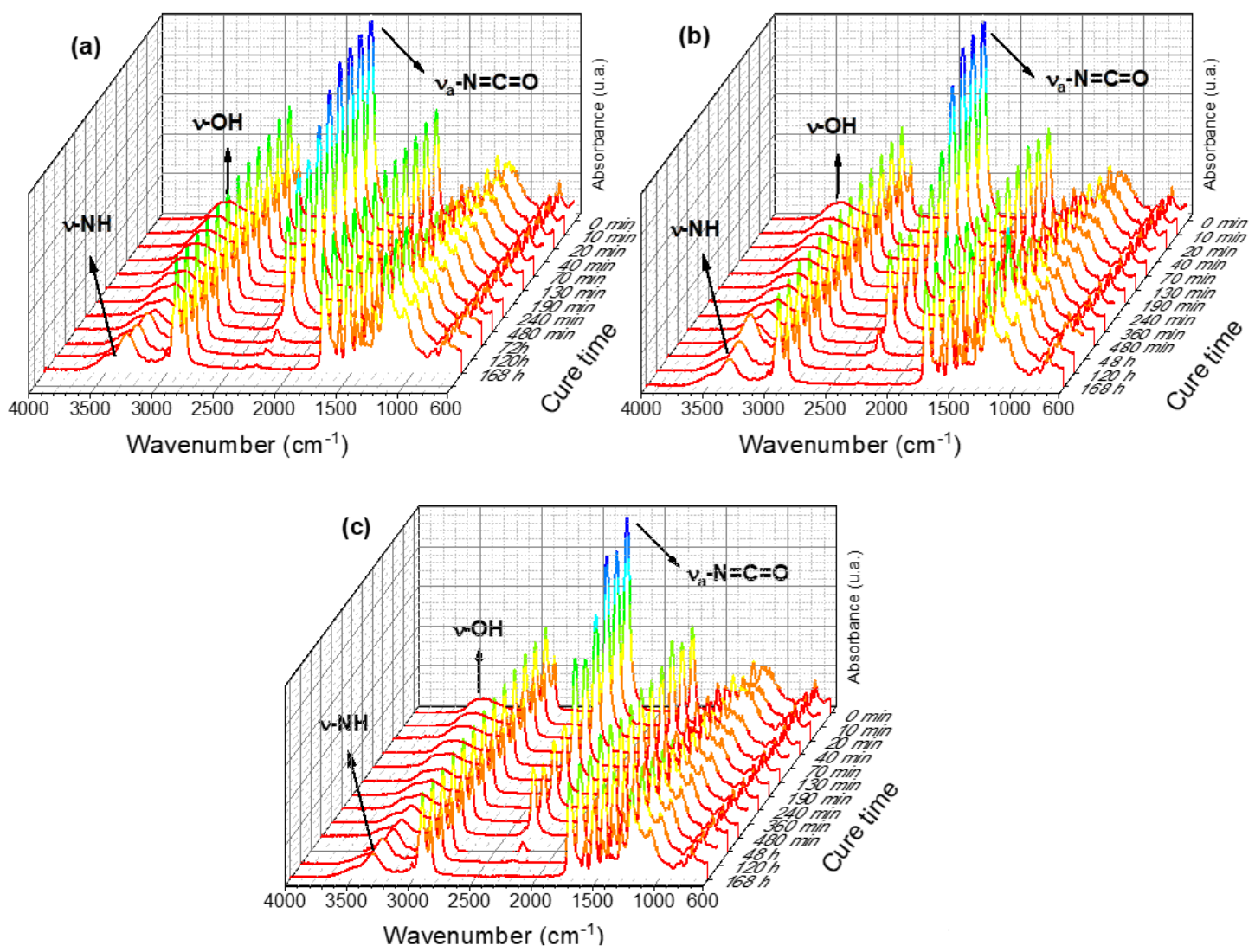

Figure 3: Normalized FTIR spectra as a function of curing time for (a) PU-Li , (b) PU-4Li and (c) PU-15Li.

Figures 3 (a) and 3 (b) revealed that, even after $168 \mathrm{~h}$, there is still a low intensity isocyanate peak at $2263 \mathrm{~cm}^{-1}$, indicating that the polymerization reaction of PU-Li and PU-4Li was not complete after $168 \mathrm{~h}$ at room temperature. In contrast, in Figure 3 (c) it can be seen that the isocyanate was totally consumed by PU$15 \mathrm{Li}$ reaction after $168 \mathrm{~h}$. The complete curing of PU-15Li might be consequence of high amount of residual catalyst in Polyol-15Li.

For a quantitative analysis of curing kinetics, isocyanate consumption (\% NCO) was calculated using equation (1) [28]:

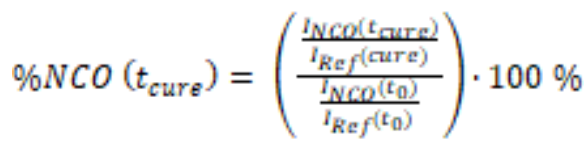

where $\mathrm{I}_{\mathrm{Ref}}$ is the intensity of the reference band $\left(2924 \mathrm{~cm}^{-1}\right.$ assigned to $v-\mathrm{CH}_{2}$ asymmetric stretching), $\mathrm{I}_{\mathrm{NCO}}$ is the intensity of the isocyanate band $\left(2263 \mathrm{~cm}^{-1}\right), \mathrm{t}_{\text {cure }}$ is the current reaction time, and $\mathrm{t}_{0}$ is the reaction time of the first measurement spectrum. 


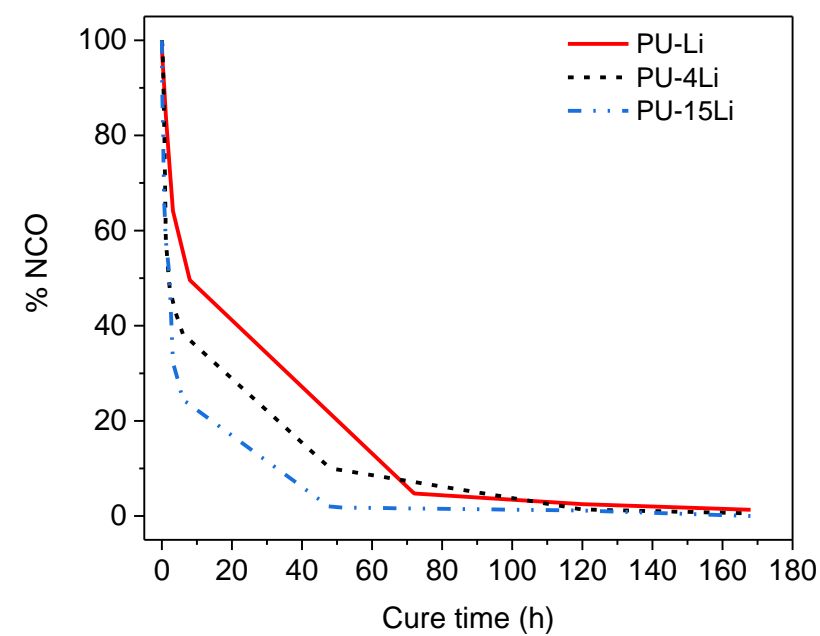

Figure 4: Isocyanate consumption $(\% \mathrm{NCO})$ as a function of PU curing time.

The isocyanate consumption was plotted as a function of the curing time in Figure 4. It can be observed in all cases that, initially the isocyanate consumption occurs at higher rates up to $10 \mathrm{~h}$ of reaction, followed by a considerable reduction in the polymerization rate. Higher initial polymerization rates might be related to high concentration of free reactive groups, which decreases during the polymerization reaction, thus decreasing the reaction rate [28].

Once polyols chemical state and polyurethane curing kinetic were discussed, mechanical results and their relation to chemical state must be stablished. The mechanical behavior of adhesively bonded joints can be strongly affected by several factors. In the case of polyurethane adhesive, factors such as $\mathrm{NCO} / \mathrm{OH}$ ratio, crosslink density and ratio between rigid and flexible segments can influence the mechanical behavior of the adhesive joint $[2,14,15]$. Moreover, when it comes to flexible laminates with an aluminum substrate, the mechanical behavior can also be influenced by changes in the aluminum composition caused by the substrate ageing, which leads to a possible reaction of the NCO with aluminum hydroxide [14].

In Figure 5 it might be observed that the values of peeling strength for the adhesives obtained from the polyols with higher concentration of the lithium catalyst are greater. This behavior can be correlated with the residual isocyanate content after polyurethane curing and the bio-polyol hydroxyl content which could influence the crosslinking density of the material. It was observed that in the case of PU-Li and PU-4Li, which still showed an isocyanate peak after $168 \mathrm{~h}$, the average peeling resistance was significantly lower than that of PU-15Li. The presence of an isocyanate peak after 168h indicates that the cure of these materials was not complete. The sample PU-15Li, which accordingly to FTIR was completely cured, might justify the higher average peeling resistance as consequence of higher crosslinking density [5].

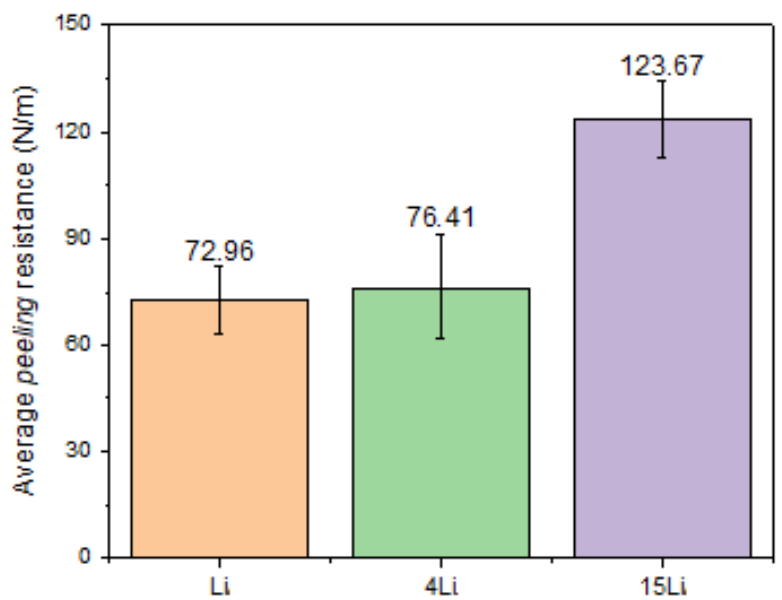

Figure 5: Laminates average peel strength. 
After peel tests, both surfaces (aluminum and PE layers) of delaminated samples were analyzed by FTIR to determine the type of failure at the adhesive joint. FTIR results are presented in Figure 6 . The presence of PU adhesive on sample surfaces was verified by FTIR through the characteristic polyurethane peaks, amine bond stretching $\left(v-\mathrm{NH}\right.$ at $\left.3325 \mathrm{~cm}^{-1}\right)$ and the stretching of the carbonyl bond $\left(1724 \mathrm{~cm}^{-1}\right)$.
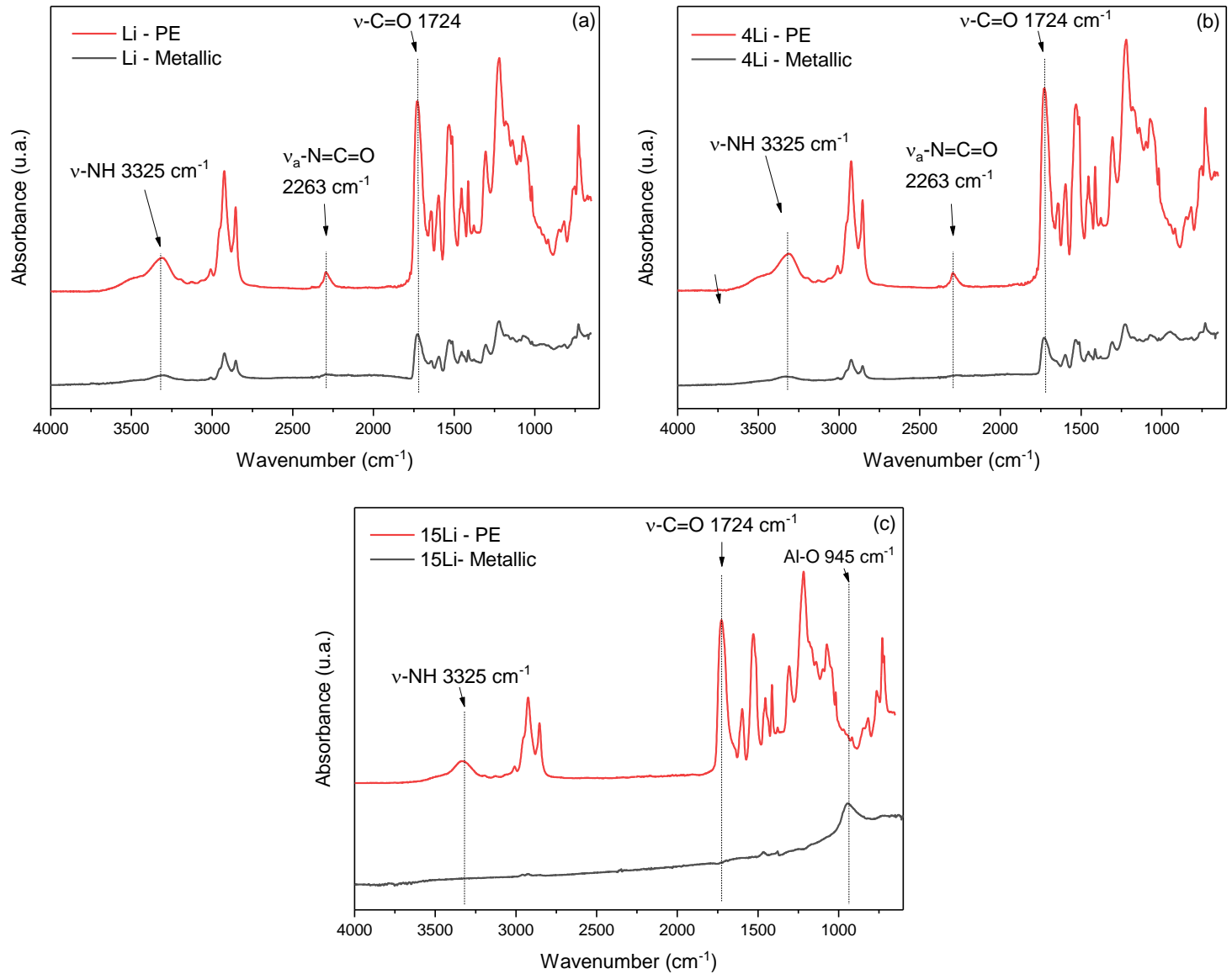

Figure 6: FTIR spectrum of the metallized and polyethylene films after the laminate peeling test of (a) PU-Li, (b) PU-4Li and (c) PU-15Li.

Figures 6 (a) and (b) indicate a cohesive failure of the adhesive, once the presence of polyurethane was confirmed on both surfaces of metallized and PE films [15]. In Figure 6 (c), the characteristic peaks of the polyurethane were not identified through this technique, on the metallized surface. The absence of characteristic PU peaks on Al surface indicated an aluminum substrate failure, which is in agreement with the peak found in $940-1000 \mathrm{~cm}^{-1}$ of $\mathrm{Al}-\mathrm{OH}$ bonds $[14,15]$. In addition, it was possible to confirm the presence of residual isocyanate only in the polyethylene substrate (PU-Li and PU-4Li) through a low intensity peak related to the asymmetric stretching of the isocyanate $\left(v_{\mathrm{a}}-\mathrm{N}=\mathrm{C}=\mathrm{O}\right.$ in $\left.2263 \mathrm{~cm}^{-1}\right)$.

\section{CONCLUSIONS}

In this work three different bio-based polyester polyols were synthesized using different catalyst concentrations. FTIR analysis showed that the increase in the lithium catalyst concentration lead to an increase in the hydroxyl content and a decrease in the viscosity of the bio-polyols, which are related to changes in the polyol physical-chemical properties as a function of the catalyst concentration. Polyol obtained with highest Li concentration generated polyurethane with complete and faster curing, besides superior peeling strength. PU$15 \mathrm{Li}$ was the unique condition that generated substrate failure (deposited $\mathrm{Al}$ layer).

\section{ACKNOWLEDGMENTS}

The authors thank CNPq (National Counsel of Technological and Scientific Development) and acknowledge the Federal University of ABC (UFABC) for the doctoral fellowship for A.M. Nacas and financial support (CNPq: 163369/2015-1). 


\section{BIBLIOGRAPHY}

[1] VALERO, M.F. "Adhesivos tipo poliuretano obtenidos a partir de aceite de ricino y almidon quimicamente modificados", Quimica Nova, v. 36, n. 5, pp. 657-662, 2013.

[2] NACAS, A.M., ITO, N.M,. SOUSA, et al., "Effects of NCO:OH ratio on the mechanical properties and chemical structure of Kraft lignin-based polyurethane adhesive", Journal of Adhesion, v. 8464, pp. 0-12, 2016.

[3] TAVARES, L.B., BOAS, C. V., SCHLEDER, G.R., et al. "Bio-based polyurethane prepared from Kraft lignin and modified castor oil", Express Polymer Letters, v. 10, n. 11, pp. 927-940, 2016.

[4] ZAIN, N.M., ROSLIN, E.N., AHMAD, S. "Preliminary study on bio-based polyurethane adhesive / aluminium laminated composites for automotive applications", International Journal of Adhesion and Adhesives, v. 71, pp. 1-9, 2016.

[5] NACAS, A.M., VIDOTTI, S.E., CHINELLATO, A.C., et al., "The role of polyol reaction catalysts in the cure kinetics and mechanical behavior of polyurethane adhesives", The Journal of Adhesion, pp. 1-13, 2017.

[6] SAHOO, S., KALITA, H., MOHANTY, S., et al., "Synthesis of Vegetable Oil-Based Polyurethane: A Study on Curing Kinetics Behavior", International Journal of Chemical Kinetics, v. 48, n. 10, pp. 622-634, 2016.

[7] CHEN, R., ZHANG, C., KESSLER, M.R. "Polyols and polyurethanes prepared from epoxidized soybean oil ring-opened by polyhydroxy fatty acids with varying OH numbers", Journal of Applied Polymer Science, v. 132, n. 1, pp. 1-10, 2015.

[8] GADDAM, S.K., PALANISAMY, A. "Anionic waterborne polyurethane-imide dispersions from cottonseed oil based ionic polyol", Industrial Crops and Products, v. 96, pp. 132-139, 2017.

[9] JAYAVANI, S. SUNANDA, S. VARGHESE, T.O., et al. "Synthesis and characterizations of sustainable polyester polyols from non-edible vegetable oils: Thermal and structural evaluation.," Journal of Cleaner Production. vol. 162, pp. 795-805, 2017.

[10] SARDON, H., PASCUAL, A., MECERREYES, D., et al. "Synthesis of Polyurethanes Using Organocatalysis: A Perspective", Macromolecules, v. 48, n. 10, pp. 3153-3165, 2015.

[11] KREYE, O. MUTLU, H., MEIER, M.R. "Sustainable routes to polyurethane precursors", Green Chemistry, v. 15, n. 6, p. 1431, 2013.

[12] DE VOS, D.E., SCHELLEKENS, Y., VAN TRIMPONT, B. et al. "Tin-free catalysts for the production of aliphatic thermoplastic polyurethanes", Green Chemistry, pp. 4401-4407, 2014.

[13] SRIDAENG, D., JITAREE, W., THIAMPANYA, P., et al. "Preparation of rigid polyurethane foams using low-emission catalysts derived from metal acetates and ethanolamine", e-Polymers, v. 16, n. 4, pp. 265-275, 2016.

[14] ITO, N.M., NACAS, A.M., ANTUNES, et al. "Study of the correlation between flexible food packaging peeling resistance and surface composition for aluminum-metallized BOPP films aged at $60^{\circ} \mathrm{C}$.," Journal of Adhesion, v. 93, n. 1-2, pp. 4-17, 2017.

[15] ITO, N.M., ANTUNES, R.A., TEIXEIRA, F. S., et al. "The peeling resistance of flexible laminated food packaging: Roles of the NCO:OH ratio and aluminum surface aging times", The Journal of Adhesion. pp. 1-15, 2017.

[16] TAVARES, L.B., ITO, N.M., SALVADORI, M.C., et al. "PBAT/kraft lignin blend in flexible laminated food packaging: Peeling resistance and thermal degradability", Polymer Testing, v. 67, pp. 169-176, 2018.

[17] ORTEGA, G.C.C., MERCADO, E.R.A., ARRIETA, B.M.C. "Transesterification vegetable oils using Heterogeneous catalysts", Prospect, v. 12, n. 2, pp. 90-104, 2014.

[18] MENEGHETTI, S.P., MENEGHETTI, M.R., and BRITO, Y.C. "A Reação de Transesterificação, Algumas Aplicações e Obtenção de Biodiesel.," Revista Virtual de Química, v. 5, n. 1, pp. 63-73, 2013.

[19] PATIL, C.K., RAJPUT, S.D., MARATHE, R.J. et al., "Synthesis of bio-based polyurethane coatings from vegetable oil and dicarboxylic acids", Progress in Organic Coatings, v. 106, pp. 87-95, 2017.

[20] D'ARCY, R., BURKE, J., TIRELLI, N. "Branched polyesters: Preparative strategies and applications.," Advanced Drug Delivery Reviews, v. 107, pp. 60-81, 2016.

[21] MCKEE, M.G., UNAL, S., WILKES, G.L., et al. "Branched polyesters: recent advances in synthesis and performance", Progress in Polymer Science, v. 30, n. 5, pp. 507-539, 2005.

[22] JACQUOT, P.-B., PERRIN, D., LÉGER, R., et al. "Impact on peel strength, tensile strength and shear 
viscosity of the addition of functionalized low density polyethylene to a thermoplastic polyurethane sheet calendered on a polyester fabric", Journal of Industrial Textiles, pp. 1-27, 2017.

[23] YANG, R., DING, L., CHEN, W., et al. "Molecular-Weight Dependence of Nucleation Effect of a Liquid Crystalline Polyester $\beta$-Nucleating Agent for Isotactic Polypropylene.," Industrial \& Engineering Chemistry Research. vol. 57, no. 19, pp. 6734-6740, 2018.

[24] SILVERAJAH, V.S.G., IBRAHIM, N.A., ZAINUDDIN, N., et al. "Mechanical, Thermal and Morphological Properties of Poly(lactic acid)/Epoxidized Palm Olein Blend", Molecules, v. 17, n. 10, pp. 1172911747, 2012.

[25] DATTA, J., GŁOWIŃSKA, E. "Effect of hydroxylated soybean oil and bio-based propanediol on the structure and thermal properties of synthesized bio-polyurethanes", Industrial Crops and Products, v. 61, pp. 84-91, 2014.

[26] UZOH, C.F., NWABANNE, J.T. "Investigating the Effect of Catalyst Type and Concentration on the functional Group Conversion in Castor Seed Oil Alkyd Resin Production", Advances in Chemical Engineering and Science, v. 6, n. April, pp. 190-200, 2016.

[27] ZHANG, C., MADBOULY, S.A., KESSLER, M.R. "Biobased Polyurethanes Prepared from Different Vegetable Oils", ACS Applied Materials \& Interfaces, v. 7, n. 2, pp. 1226-1233, 2015.

[28] ZIMMER, B., NIES, C., SCHMITT, C., et al., "Chemistry, polymer dynamics and mechanical properties of a two-part polyurethane elastomer during and after crosslinking. Part I: dry conditions", Polymer, v. 115, pp. 77-95, 2017.

[29] COATES, J. "Interpretation of Infrared Spectra, A Practical Approach", Encyclopedia of Analytical Chemistry, pp. 1-23, 2006.

[30] LEVERD, F., FRADET, A., MARÉCHAL, E. "Study of model esterifications and of polyesterifications catalyzed by various organometallic derivatives-II. Study of esterifications and polyesterifications catalyzed by zirconium derivatives", European Polymer Journal, v. 23, n. 9, pp. 699-704, 1987.

[31] LILJA, J., MURZIN, D.Y., SALMI, T., et al., "Esterification of different acids over heterogeneous and homogeneous catalysts and correlation with the taft equation", Journal of Molecular Catalysis A: Chemical. v. 182 , n. 183 , pp. 555-563, 2002.

[32] FUG, F., NIES, C., POSSART, W. "In situ FTIR study of adhesive interactions of 4,4' -methylene diphenyl diisocyanate and native metals", International Journal of Adhesion and Adhesives, v. 52, pp. 66-76, 2014.

[33] NIES, C., FUG, F., OTTO, C., et al. "Adhesion of polyurethanes on native metal surfaces - stability and the role of urea-like species", International Journal of Adhesion and Adhesives, v. 52, pp. 19-25, 2014.

[34] HUACUJA-SÁNCHEZ, J.E., MÜLLER, K., POSSART, W. "Water diffusion in a crosslinked polyether-based polyurethane adhesive", International Journal of Adhesion and Adhesives, v. 66, pp. 167-175, 2016.

\section{ORCID}

Amanda Martins Nacas Anne Cristine Chinellato Demetrio Jackson dos Santos http://orcid.org/0000-0002-0720-9806

http://orcid.org/0000-0002-1090-3241

http://orcid.org/0000-0002-4707-2285 